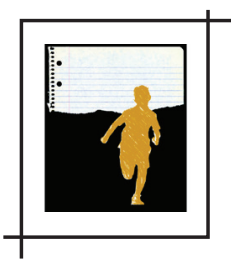

\title{
A DIMENSÃO PEDAGÓGICA DO CINEMA NEGRO E A AUTOESTIMA PARA O DESENVOLVIMENTO DA CRIANÇA NA ESCOLARIDADE
}

\author{
Celso Luiz Prudente* \\ Silvana dos Santos Costa Oliveira**
}

Resumo: Este trabalho consiste em desenvolver uma reflexão crítica sobre o papel da autoestima no desenvolvimento da criança na escolaridade monocultural, que é excludente. Com base nisso, a categoria da dimensão pedagógica do cinema negro poderá contribuir para a superação que é imposta aos negros como minoria. Observamos que, na sociedade contemporânea, as lutas e pautas raciais, socioeconômicas e culturais transcenderam o campo das letras e se transformaram em lutas de imagem, que se projetaram em lutas de classe, e, desse modo, as produções audiovisuais ganharam mais espaço e importância. Considerando que as identidades são construídas na relação do eu com o outro (HALL, 2011), podemos afirmar que a mídia tem tentado influenciar a imagem que a criança tem de si, o que pode também influenciar a autoestima das crianças ao não se verem representadas. Nesse contexto, o cinema negro tem demonstrado que sua dimensão pedagógica (PRUDENTE; PASSOS; CASTILHO, 2011; OLIVEIRA; PRUDENTE, 2017; PRUDENTE, 2019a, 2019b, 2019c, 2020) é fundamental na medida em que se transformou em representante dos grupos vulneráveis minorizados na sociedade que é impregnada pela euro-heteronormatividade, fenômeno determinante para o autoritarismo da verticalidade da hegemonia imagética do euro-hétero-macho-autoritário, na tentativa de negação da horizontalidade da imagem do ibero-ásio-afro-ameríndio como grupo minoritário e a minoria como um todo.

Palavras-chave: Cinema negro. Infância. Autoestima. Escolarização. Identidade.

\section{INTRODUÇÃO}

Desde a segunda metade do século XX, a discussão sobre as relações raciais no contexto da educação brasileira aumentou de forma considerável, especialmente nas universidades e nos movimentos sociais.

\footnotetext{
* Pós-doutor em Linguística pela Universidade Estadual de Campinas (Unicamp) e doutor em Cultura pela Universidade de São Paulo (USP). Professor associado da Universidade Federal de Mato Grosso (UFMT). Antropólogo, cineasta, curador da Mostra Internacional do Cinema Negro e pesquisador do Centro de Estudos Latino-Americanos sobre Cultura e Comunicação (Celacc) da USP. E-mail:clsprudente@gmail.com

** Mestranda em Educação da Universidade Federal de Mato Grosso (UFMT), na linha de pesquisa Movimentos Sociais, Politica e Educação Popular. Professora de lingua inglesa na rede estadual de Várzea Grande, em Mato Grosso. E-mail: money. silvana@gmail.com
} 
Certamente em um país poliétnico, marcado por desigualdades econômicas, sociais e raciais, a aprendizagem sobre aspectos históricos e culturais dos vários povos africanos que formaram a nação brasileira poderia contribuir para a afirmação positiva da imagem do ibero-ásio-afro-ameríndio (PRUDENTE, 2019b) .

Contudo, as dificuldades e os desafios foram muitos até a aprovação da Lei Federal n. 10.639/2003, que tornou obrigatório o ensino de história e da cultura africana nas escolas brasileiras. Todavia, a aplicação efetiva dessa lei deixou evidente a dificuldade dos governos em ofertar formação adequada aos profissionais, pois há resistências de alguns segmentos da sociedade e da própria comunidade escolar na compreensão da importância dos ensinamentos, inserindo-as nesse contexto no cotidiano escolar.

Nesse sentido, alguns estudos da Universidade Federal de Mato Grosso (UFMT) apontam o modo estereotipado como a cultura e a história dos afrodescendentes são tratadas no ambiente escolar. Santana (2013), em suas pesquisas com diretores e estudantes de duas escolas públicas de Cuiabá-MT, afirma que apesar de constarem no Projeto Político-Pedagógico (PPP) das escolas, o negro e sua cultura são evidenciados somente próximos às datas comemorativas, como o Dia da Consciência Negra. Outra pesquisa realizada por Alexandre (2010) com alunos e professores de uma escola em Sinop-MT conclui que as discussões sobre a temática racial são evitadas ou discutidas, questionando se têm ou não relevância.

Ambas as pesquisas evidenciam que os estudantes negros vão construindo suas identidades com poucas referências positivas, o que interfere possivelmente na própria percepção que têm de si e dos outros.

Então, no presente estudo discutiremos o conceito emergente de dimensão pedagógica do cinema negro por meio dos estudos de Prudente, Passos e Castilho (2011) e Prudente (2018, 2019a, 2019b, 2020) e a influência da autoestima no processo de escolarização de crianças negras.

Desse modo, além deste texto introdutório, estruturaremos este artigo em três divisões principais. Na primeira, traremos reflexões acerca das relações raciais na escolaridade brasileira do ponto de vista da história da aprendizagem e apresentaremos alguns dados com indicadores educacionais. Na segunda, trataremos das relações entre autoestima e aprendizagem, incluindo a influência da mídia na construção da autoimagem, e, na terceira, abordaremos aspectos do emergente conceito dimensão pedagógica do cinema negro de Celso Prudente e de seu papel libertador e democrático em relação às minorias.

1 - Categoria conceitual emergente de Prudente (2019b) que reúne os seguintes povos e seus descendentes: ibéricos, africanos, asiáticos e indigenas das Américas. 


\section{REFLEXÕES SOBRE RELAÇÕES RACIAIS NA ESCOLARIDADE BRASILEIRA}

Segundo dados do Instituto Brasileiro de Geografia e Estatística - IBGE (2018), aproximadamente 56\% da população brasileira se declara negra (de cor preta e parda), contudo os indicadores sociais dessa população permanecem piores do que a da população autodeclarada branca. Por exemplo, na área da educação, enquanto 4,3\% dos brancos brasileiros não tiveram acesso à instrução, entre os negros o percentual é de 9,3\%, e entre os que concluíram o ensino superior, os percentuais são de $24 \%$ e $10,1 \%$, para brancos e negros, respectivamente.

Esses dados refletem todo o processo da eurocolonização (PRUDENTE, 2019b) ocorrido no Brasil ocidental, no qual as populações de origem africana e ameríndia tiveram seus direitos humanos fundamentais desrespeitados. Desde a chegada dos portugueses ao Brasil até meados do século XVII, o ensino tinha caráter primário e catequista para os nativos e de formação de dirigentes para os filhos dos colonizadores, que poderiam cursar a formação primária e a formação média (formação de bacharéis em letras e mestres em artes, exclusivo para os filhos dos coronéis), sendo exercido pelos jesuitas até 1759, ano em que foram expulsos do Brasil pelo marquês de Pombal.

Portanto, desde o periodo colonial os negros africanos e seus descendentes estiveram à margem do processo de escolarização, sendo excluídos tanto pelo Estado que legislava em desfavor dos negros quanto pelos que detinham o poder econômico, que criavam mecanismos cujo objetivo era proibir ou dificultar o acesso à educação formal.

A Constituição Federal de 1824, em seu artigo $6^{\circ}$, exclui os negros do direito à nacionalidade brasileira, como segue:

\section{Art. 6. São Cidadãos Brazileiros}

I. Os que no Brazil tiverem nascido, quer sejam ingenuos, ou libertos, ainda que o pai seja estrangeiro, uma vez que este não resida por serviço de sua Nação.

II. Os filhos de pai Brazileiro, e Os illegitimos de mãi Brazileira, nascidos em paiz estrangeiro, que vierem estabelecer domicilio no Imperio.

III. Os filhos de pai Brazileiro, que estivesse em paiz estrangeiro em sorviço do Imperio, embora elles não venham estabelecer domicilio no Brazil.

IV. Todos os nascidos em Portugal, e suas Possessões, que sendo já residentes no Brazil na época, em que se proclamou a Independencia nas Provincias, onde habitavam, adheriram á esta expressa, ou tacitamente pela continuação da sua residencia.

V. Os estrangeiros naturalisados, qualquer que seja a sua Religião. A Lei determinará as qualidades precisas, para se obter Carta de naturalisação (BRASIL, 1824, grifo nosso).

Consequentemente, ficaram excluídos das políticas públicas de Estado, inclusive sendo formalmente impedidos de frequentar a escola, direito concedido apenas aos brasileiros, conforme artigo 94, inciso II, da Constituição de 1824, como segue: 
Art. 94. Podem ser Eleitores, e votar na eleição dos Deputados, Senadores, e Membros dos Conselhos de Provincia todos, os que podem votar na Assembléa Parochial. Exceptuam-se [...]

II. Os Libertos (BRASIL, 1824, grifo nosso).

Nota-se que inúmeras foram as tentativas de cerceamento do direito dos negros à educação, como observado no Decreto n. 1.331, de fevereiro de 1854, cujo objetivo era proibir que os escravos tivessem acesso às escolas públicas:

Art. 69. Não serão admittidos á matricula, nem poderão frequentar as escolas:

$\S 1^{\circ}$ Os meninos que padecerem molestias contagiosas.

$\S 2^{\circ}$ Os que não tiverem sido vaccinados.

$\S 3^{\circ}$ Os escravos (BRASIL, 1854, grifo nosso).

Com a mesma lógica, demonstramos que o Decreto n. 7.031, de setembro de 1878, permitia que os negros libertos frequentassem o ensino público no período noturno, o que dependeria da boa vontade de seus senhores, haja vista o fato de que o trabalho livre ainda era impregnado de relações escravistas. Assim, os negros e seus descendentes tinham poucas chances de acesso à instrução formal, dependendo de iniciativas de alguns coronéis e de outros negros que sabiam ler e escrever, como foi decretado:

Art. $5^{\circ}$ Nos cursos nocturnos poderão matricular-se, em qualquer tempo, todas as pessoas do sexo masculino, livres ou libertos, maiores de 14 annos. As matriculas serão feitas pelos Professores dos cursos em vista de guias passadas pelos respectivos Delegados, os quaes farão nellas as declarações da naturalidade, filiação, idade, profissão e residencia dos matriculandos (BRASIL, 1878).

Nesse contexto, poucos tiveram acesso à educação formal ofertada pelo Estado, que era restrita aos que detinham privilégios econômicos, e, conforme o censo de 1872, 82,3\% da população brasileira com mais de 5 anos era analfabeta (BRASIL, 1920).

Então, no período imperial, ainda que não divulgadas nos livros de história oficial, várias foram as iniciativas que partiram de negros e pardos para permitir sua escolarização e dos seus. Entre as instituições que participaram desse movimento, destacam-se: o educandário fundado no Rio de Janeiro por Pretextato dos Passos e Silva, que funcionou de 1853 a 1873 no Rio de Janeiro (SILVA, 2002); a Escola da Perseverança, fundada pelo professor Antonio Ferreira Cesarino Junior em Campinas, São Paulo, que funcionou de 1860 a 1876, voltada para o ensino de afrodescendentes, mas que recebia alunas brancas no período vespertino e mantinha a escola com as mensalidades pagas pelas familias dessas discentes; o internato 
em Paracatu, Minas Gerais, dirigido por Bernardina Cesarino e suas irmãs, que recebia alunas brancas que pagavam mensalidade e atendia alunas negras (PEREIRA, 1999), entre outras.

Portanto, vale lembrar que "ao longo de grande parte da nossa história essa questão [do analfabetismo] não esteve posta" (PAIVA, 1990, p. 9), e as discussões sobre a temática ganham maior destaque após a chegada da corte portuguesa ao Brasil, em 1808.

Durante o século XIX, realizaram-se algumas reformas nos sistemas de ensino e criaram-se escolas de formação docente, as escolas normais, contudo o Estado não realizou os investimentos necessários para promover o acesso ao ensino e garantir a permanência dos estudantes, especialmente dos mais pobres.

$\mathrm{Na}$ Constituição Federal de 1934, há um capítulo inteiro sobre educação, entretanto esta só passa a ser direito de todos na década seguinte, na Constituição de 1946: "Art. 166 - A educação é direito de todos e será dada no lar e na escola" (BRASIL, 1946). Portanto, o ensino primário passa a ser direito de todo cidadão e a educação para o trabalho passa a ser valorizada.

Durante a era Vargas, várias foram as reformas no sistema educacional com vistas a transformar o país de rural em urbano-industrial. Então, o Sistema Nacional de Aprendizagem Industrial (Senai) foi criado em 1942 com o objetivo de educar, especialmente as camadas pobres da população, para o novo modelo de trabalho. Podemos considerar que a década de 1940 marca o sistema educacional brasileiro com a expansão das escolas secundaristas e técnicas em vários estados, o que amplia o acesso da população ao ensino público, que aos poucos vai perdendo seu caráter elitista.

Ressalta-se que, apesar de ser um direito de todos, o ensino púbico não era acessivel a todos por inúmeras razões, seja de ordem econômica, social, racial e de gênero etc. Nesse cenário marcado pelas desigualdades regionais e sociais, Paulo Freire ganha projeção nacional por seu projeto desenvolvido na alfabetização de adultos carentes. E, influenciadas por seus ensinamentos, surgem diversas iniciativas de combate ao analfabetismo no Brasil. A consolidação do reconhecimento do método de alfabetização de Paulo Freire deu-se com o convite feito pelo presidente João Goulart ao educador pernambucano para elaborar o Plano Nacional de Alfabetização. Contudo, essa ação foi abortada em razão do golpe militar de 1964, que depôs João Goulart. No entanto, a organização e sistematização das redes de ensino, que poderiam ter ajudado a combater o analfabetismo, só viriam mais tarde com a promulgação da Lei de Diretrizes e Bases da Educação (LDB).

A primeira versão da LDB, em 1961 (Lei n. 4.024/1961), além de instituir as disciplinas, descentraliza o poder do Ministério da Educação (MEC), dá certa autonomia para os estados (artigo 10), garante um percentual de recursos para investimentos em educação (artigo 92) e torna obrigatória a matrícula nos quatro anos do ensino primário (artigo 31) (BRASIL, 1961). Já em 1971, a Lei n. 5.692/1971, em seu artigo 20, amplia a obrigatoriedade do ensino de primeiro grau (de 7 a 14 anos), prevê investimento de 20\% da receita dos municípios em 
educação (artigo 59) e prevê um núcleo comum para o currículo de primeiro e segundo graus e uma base diversificada (artigo 4) (BRASIL, 1971).

A Lei n. 9.394/1996, cujo relator foi Darcy Ribeiro, vem atender ao disposto nos artigos 205 a 214 da Constituição Federal de 1988 e reflete muitos dos debates presentes nas universidades desde a década de 1960, tais como: universalização do ensino público, melhoria da qualidade do ensino público, qualificação dos profissionais da educação, gestão democrática nas escolas, inclusão social, formação integral do cidadão etc.

Apesar dos avanços educacionais ocorridos no Brasil, as questões raciais ${ }^{2}$ precisam ser consideradas quando falamos em educação. As redes de ensino atuais são resultantes de um sistema de tendência eurocêntrica caucasiana, pensado para excluir negros, indígenas e brancos pobres, que formam uma massa miscigênica caracterizada com a imagem de horizontalidade do ibero-ásio-afro-ameríndio, que ficaram à margem da sociedade, sendo excluídos quer seja por não terem acesso legal aos colégios ou condições de permanecer nele, mantendo as "elites" no poder político e, consequentemente, exercendo o poder econômico que se dá na verticalidade imagética do euro-hétero-macho-autoritário (PRUDENTE, 2019c).

As consequências nefastas da marginalização desses grupos podem ser observadas nas pesquisas de indicadores sociais publicados por diversas instituições nacionais e internacionais, como o IBGE e a Organização das Nações Unidas para a Educação, a Ciência e a Cultura (Unesco), como podemos observar na Tabela 1.

Tabela 1 Taxa de analfabetismo

\begin{tabular}{|c|c|c|c|}
\hline \multirow{4}{*}{ Região } & \multicolumn{3}{|c|}{ Taxa de analfabetismo das pessoas de 15 anos ou mais de idade } \\
\hline & & \multicolumn{2}{|c|}{ Cor ou raça } \\
\hline & Total & Branca & Preta ou parda \\
\hline & \multicolumn{3}{|c|}{ Proporção } \\
\hline Brasil & 6,8 & 3,9 & 9,1 \\
\hline Norte & 8,0 & 5,9 & 8,4 \\
\hline Nordeste & 13,9 & 10,7 & 14,9 \\
\hline Sudeste & 3,5 & 2,4 & 4,7 \\
\hline Sul & 3,6 & 2,7 & 6,7 \\
\hline Centro-Oeste & 5,4 & 3,7 & 6,4 \\
\hline
\end{tabular}

Fonte: Pesquisa Nacional por Amostra de Domicílios Contínua do segundo trimestre de 2018 (INSTITUTO BRASILEIRO DE GEOGRAFIA E ESTATÍSTICA, 2018)3.

2 - Do ponto de vista sociológico, trata-se de uma construção social usada para distinguir um grupo de pessoas por caracteristicas especificas. A percepção dessa construção pode afetar e organizar a vida social das pessoas e o modo como são vistas em uma sociedade (FERNANDES, 1978, p. 7).

3 - Tabela simplificada e adaptada para este trabalho. Indigenas, amarelos e pessoas sem declaração de cor ou raça constam no total. 
Podemos observar que, em nivel federal, as taxas de analfabetismo entre os negros são maiores do que as dos brancos, quando consideramos as cinco regiões brasileiras, e provavelmente esses dados refletem todo o processo histórico de exclusão sociorracial pelo qual passaram.

A abolição da escravidão em 1888 não garantiu aos negros e aos seus descendentes quaisquer reparações econômicas dos danos causados pelo crime de escravidão (PRUDENTE, 2006), nem garantiu políticas públicas reparadoras para reintegrar os "libertos" à sociedade brasileira, com garantia de direitos básicos como moradia, educação e emprego (PRUDENTE, (2019c).

Essa exclusão racial não apenas impediu o acesso de grande parcela da população negra ao ensino formal, mas também pode ter contribuído para o insucesso escolar de muitos estudantes, pois a escola como foi pensada no Brasil estava distante de sua realidade.

Nesse sentido, o sociólogo Pierre Bourdieu (1999, p. 71-79) conceitua habitus ou "capital cultural incorporado" como um sistema em que estão incorporadas disposições e tendências que organizam o mundo social e a ele reagem e é adquirido pela representação. Ou seja, uma parcela significativa entre os indivíduos, oriundos das classes desfavorecidas econômica e socialmente, como os afrodescendentes, provavelmente se sentirão outsiders (ELIAS; SCOTSON, 2000) dentro de um sistema educacional secularmente construido para segregá-los.

Por isso, as lutas dos movimentos sociais foram e são essenciais para a continuidade das mudanças estruturais no Estado brasileiro, que tem na educação um dos pilares, como o Teatro Experimental de Negro (TEM), o Movimento Negro Unificado (MNU), os Coletivos Negros Universitários e outras organizações que lutam pelos direitos das minorias ao acesso a um ensino público, gratuito e de qualidade, desde a creche até universidade, contra a violência policial e contra o racismo.

Nesse breve histórico, pode-se notar que a escolaridade brasileira sempre foi marcada por contradições, desigualdades e violações de direitos das minorias, que tiveram seu acesso proibido ou dificultado no ambiente escolar e que este foi construido para atender às classes dominantes.

Do mesmo modo, o combate ao analfabetismo entre a população em geral não era prioridade do Estado desde o período colonial até o início do século passado e passa a ter relevância por questões políticas, visto que o Brasil projetava sua imagem internacional com um ideal de país urbano industrial e em pleno desenvolvimento, alinhado com as posições geopolíticas e econômicas do governo dos Estados Unidos. Para justificar esse ideal, foi preciso aumentar, pelo menos aparentemente, o percentual da população alfabetizada e mais adaptável ao trabalho nas indústrias que se instalavam nos centros urbanos, reconfigurando o sistema de exploração dos trabalhadores.

Essa "adaptação forçada" ao novo regime de trabalho muda a forma como as pessoas se veem e se posicionam na sociedade, influencia as políticas públicas educacionais para aten- 
dimento da classe trabalhadora e altera a própria geografia das cidades, com o aumento de favelas e habitações precárias.

Então, tais mudanças provavelmente provocaram transformações na autoestima e na autoimagem dessa população, especialmente das crianças. Portanto, discutiremos a seguir algumas relações entre a autoestima e a escolarização na infância.

\section{A CONSTRUÇÃO DA AUTOESTIMA E A ESCOLARIZAÇÃO NA INFÂNCIA}

Partindo-se do princípio constitucional do direito à educação (BRASIL, 1988) e de que toda criança precisa se sentir incluida no ambiente escolar, a Lei n. 9.394/1996 - LDB determina que sejam feitas adequações do ensino à realidade regional ou local dos estudantes, a pluralidade de ideias e metodologias e a valorização da diversidade cultural brasileira, (BRASIL, 1996).

A escola é vista como um espaço de socialização, e, por isso, o acolhimento dos estudantes na educação infantil e nos anos iniciais do ensino fundamental é primordial e pode garantir maior sucesso e adaptação ao ambiente escolar.

Considerando que as crianças estão sujeitas às dificeis relações raciais conflituosas e que a autoestima pode influenciar o processo de aprendizagem e é desenvolvida a partir da interiorização da estima que se tem por ela e da confiança da qual ela é alvo, torna-se necessária a viabilização de políticas públicas de ação afirmativa para a promoção da saúde física e emocional dos estudantes.

Todavia, a eurocolonização deixou marcas profundas na sociedade ocidental, e as mídias refletem a euro-heteronormatividade (PRUDENTE, 2019b) ${ }^{4}$ do pensamento ocidental. A representatividade dos grupos socialmente minorizados é pífia ou estereotipada na mídia, especialmente em relação ao público infantil, cujas produções são dominadas pelos grandes conglomerados eurocêntricos.

Na literatura infantojuvenil, muito adaptada para o cinema em forma de filmes e desenhos animados, raramente vemos personagens negros ou ameríndios como heróis ou heroínas. Geralmente, estes assumem um papel secundário ou são representados como anti-heróis.

Então, características relacionadas à "beleza", ao "sucesso", à "bravura" e à "força" comumente estão associadas ao fenótipo mais próximo ao eurocolonizador, como podemos observar nos príncipes e nas princesas dos contos de fadas produzidos e veiculados pela Disney e nos heróis e nas heroínas da Marvel ou Disney, salvo algumas exceções.

4 - Conceito emergente de Prudente (2019b) para designar as relações de poder e as normalidades decorrentes da visão de mundo eurocêntrica. 
No contexto brasileiro, poucos personagens de produções voltadas ao público infantil são negros e amerindios, como em telenovelas, séries e outras produções de entretenimento. Não são raras as associações desses fenótipos a estereótipos raciais, relacionados à cor da pele, à textura capilar, à cultura e à religião desses povos. Assim, com poucas referências positivas, as crianças vão construindo suas identidades por meio da negação de sua ancestralidade, o que pode impactar a autoestima e interferir no processo de escolarização.

Conforme Tiba (2002, p. 147), autoestima é "o sentimento que faz com que a pessoa goste de si mesma. Aprecie o que faz e aprove suas atitudes". Desse modo, quando a criança tem uma imagem positiva de si, provavelmente a aprendizagem será significativa.

A psicologia social, em estudos que pretendiam investigar as representações sociais, a memória e o imaginário, também mostra alguns aspectos relacionados à construção das identidades do "eu" e do "outro" e aborda os estágios de afirmação em relação ao pertencimento a este ou àquele grupo.

As práticas escolares supervalorizam a cultura europeia em detrimento de outras, a exemplo de alguns livros didáticos e paradidáticos que continuam a representar o negro e o judeu em posições subalternas ou associam sua imagem apenas à escravidão e a estereótipos. Portanto, ao não se identificarem física e culturalmente com os referenciais apresentados na escola, essas crianças podem desenvolver baixa autoestima e até ter o rendimento escolar prejudicado.

Para Algarve (2004, p. 16), a escola tem um papel importante na formação da identidade e da intelectualidade das crianças, sendo necessário que ela trabalhe com referenciais que representem a diversidade étnica cultural brasileira.

Como novo referencial curricular para a educação brasileira, a Base Nacional Comum Curricular (BNCC) apresenta competências socioemocionais em todas as dez competências gerais para a educação básica e dedica a competência oito para tratar de questões relacionadas ao autocuidado e autoconhecimento (BRASIL, 2017). Também traz a concepção de criança como um ser histórico e social, e, por isso, os currículos escolares precisam contemplar o bem-estar físico emocional e social dela. A relação aprendizagem e emoção já foi discutida sob diversas perspectivas na biologia, na neuropsicologia, na psicopedagogia, entre outros ramos das ciências.

Autoestima e aprendizagem estão diretamente relacionadas na medida em que as dificuldades para aprender podem provocar baixas na autoestima e na valorização pessoal, o que pode interferir no processo de aprendizagem. Sabendo que a interação da criança com os demais atores no ambiente escolar é determinante na aprendizagem e que essas relações de poder nem sempre são harmônicas, estudos sobre a influência da autoestima no processo de escolarização da criança tem ganhado relevância nas últimas décadas.

Ademais, a concepção de criança como ser histórico e social muda a perspectiva em relação ao papel dela no processo, a sua importância e o seu protagonismo passam a ser consi- 
derados durante a aprendizagem, e fatores como os socioemocionais precisam ser levados em conta. Por isso, práticas humanistas holísticas e de valorização da autoestima e do autoconceito da criança poderiam contribuir positivamente durante sua escolarização.

Desse modo, a dimensão pedagógica do cinema negro poderá contribuir para que professores e estudantes ampliem seus conhecimentos sobre a arte negra, desconstruindo os patológicos preconceitos e os anacrônicos estereótipos amplamente disseminados pela mídia que prejudicam a inserção de contemporaneidade necessária no processo de reconstrução do autoconceito e da autoimagem.

\section{A DIMENSÃO PEDAGÓGICA DO CINEMA NEGRO}

Durante muito tempo, a imagem do Brasil como um exemplo de democracia racial a ser seguido foi propagada mundo afora, mas a realidade que aqui se vivia era bem diferente. Para Prudente (2019c), a revolução tecnológica tem como uma de suas consequências uma luta imagética e encontra na informação seu elemento substancial, e é inequívoco o discernimento de que a imagem é conhecimento na medida em que a imagem é informação.

Ainda em relação a essa luta de representação iconográfica ontológica, em que se dá a imagem da afirmação positiva do ibero-ásio-afro-ameríndio versus a lógica linear mercantilista do pensamento europeu materializada na hegemonia do euro-hétero-macho-autoritário ${ }^{5}$, Oliveira e Prudente (2017, p. 113) afirmam:

\footnotetext{
É sensato supor que na era da revolução tecnológica a dimensão social do indivíduo está na representação, e a pessoa é de uma significação especifica que não encontra lugar nas redes, sendo uma possivel pessoalidade sem exterioridade gregária, pois esta demanda se estabelece em uma relação de rede onde as expressões decorrem da forma, distanciando-se das possibilidades de conteúdo, fenômeno coadunável com a homogeneização da pós-modernidade que pasteuriza as relações, fragmentando os valores da individualidade.
}

Podemos observar o autoritarismo imagético diariamente na mídia, nas escolas, na política e na sociedade. Devemos considerar que, apesar de os negros representarem "maioria absoluta" da população brasileira, tornaram-se uma "maioria minorizada", pois foi "absolutamente diminuto em relação ao poder socioeconômico", que privilegiou socialmente os que se aproximavam do fenótipo eurocaucasiano (PRUDENTE, 2019c, p. 10).

5 - Conceito emergente criado por Celso Luiz Prudente para se referir ao grupo hegemônico que demonstra essência do poder euro-ocidental que passa pela dinâmica da sociedade patriarcal. 
Portanto, os ibero-ásio-afro-ameríndios estão sub-representados na mídia, suas religiões e seus cultos ainda são estigmatizados ou desprezados, suas características fenotípicas são representadas por meio de estereótipos raciais nas telenovelas (ARAÚJ0, 2003), nos comerciais de televisão, nos desenhos animados etc., o que colabora com a aviltação de sua imagem e influência na construção de sua identidade (HALL, 2011)6.

Conforme Prudente, Passos e Castilho (2011, p. 89), "na era da cibernética, que se encontra nos estágios mais avançados da inteligência e da vida artificial, as lutas de classe se dão em uma dinâmica imagética: de luta de imagem".

Em relação a essa luta imagética, Santos (2010) afirma que um grupo social dominante tenta fazer uso das mídias para propagar seu imaginário e seus discursos de poder que intervêm na memória coletiva. Para garantir essa dominação simbólica, o controle dos meios de comunicação de massas é fundamental, pois esse suporte tecnológico assegura a circulação de informações e imagens, registrando na memória coletiva signos e símbolos que contribuirão na formação do imaginário social.

Desse modo, a escola como espaço de convivência democrática e diversa poderá influenciar positivamente inúmeras mudanças na estrutura do pensamento e da organização da sociedade, e, por isso, acreditamos que a Lei n. 10.639/2003, que incluiu no currículo oficial da rede de ensino a obrigatoriedade da temática história e cultura afro-brasileira, significou um enorme avanço na legislação brasileira, pois reconhece a importância desses povos na formação da nação brasileira.

Então, o grande desafio é colocar a legislação em prática no cotidiano escolar, incluindo no PPP discussão horizontal com a comunidade que, por meio dos filhos, vive o processo das práticas cotidianas da escola. Dessa maneira, essas ações que contemplam o ensino da história, cultura e literatura dos povos africanos e indígenas deverão ser o reflexo da dinâmica desses grupos étnico-raciais em demanda emergencial. Essa possibilidade pressupõe uma transformação significativa nas relações institucionais, considerando que o ainda problema monocultural da escolaridade é por sua vez um fator paradigmático. Razão pela qual acreditamos que a democratização escolar em uma sociedade poliétnica demanda a incorporação horizontal dos nomos de todas as correntes étnicas e raciais, que reclamam a marginalização. Isso se dá incluindo todos os atores da escolaridade. De tal sorte que a mera consideração cosmética dos valores emergentes ainda coloca o problema da imposição de paradigma, favorecendo a axiologia euro-ocidental caucasiana. Dessa maneira, sugerimos que a felicidade da possível reforma democrática da escolaridade deverá estar em consonância com a dinâmica emergencial que se estabelece fora da escola. Sem esse

6 - Para Hall (2011), a identidade do sujeito pós-moderno é formada por várias identidades, por vezes contraditórias. A identidade é o ponto de sutura entre os discursos e as práticas que tentam nos interpelar. 
equilíbrio de fora e de dentro, o esforço reformista no ambiente escolar certamente mostrará inequívoca fragilidade.

Em diálogo com Spivak (2010), notamos que a crítica à hegemonia euro-ocidental tem se dado no limite de um sujeito hegemônico, em que a fala tem como limite a razão e a euro-ocidentalidade caucasiana que, infelizmente, não se mostra sensivel à heterogeneidade dos não ocidentais. De tal sorte que, em conformidade com Spivak (2010), vamos inferir a possibilidade da revisão da crítica, que coloca em questão os outros valores que se fazem esquecidos na representação de caráter agenciado do estabelecido, mantendo-o ainda como sujeito, quando o que se busca é o outro como sujeito, razão pela qual se torna urgente a sua fala, cuja emergência é configurada na revisão da crítica na demanda da representação. Pois a representação do outro como crítica ainda tenta Ihe furtar a condição de sujeito, que requer a sua fala por si mesmo como revisão crítica do estabelecido na esfera de um possível espaço temporal hegemônico, do ocidentalismo. Dessa maneira, a condição de sujeito do diverso tem como condição de causa pétrea a sua fala como corporalidade e confirmação emergencial da sua temporalidade existencial, que é a sua própria história, como fala que rompe com a subordinação de representação hermenêutica dentro do autoritário com o texto universal do euro-ocidentalismo. Essa nossa compreensão se inferiu em Spivak (2010, p. 21), quando escreve:

Algumas das críticas mais radicais produzidas pelo Ocidente hoje são o resultado de um desejo interessado em manter o sujeito do Ocidente, ou o Ocidente como Sujeito. [...] Embora a história da Europa como Sujeito seja narrada pela lei, pela economia política e pela ideologia do Ocidente, esse Sujeito oculto alega não ter "nenhuma determinação geopolítica". Assim, a tão difundida crítica ao sujeito soberano realmente inaugura um Sujeito.

Na sociedade contemporânea, o cinema é um dos meios de comunicação de massa mais acessiveis às crianças e aos adolescentes, e o uso de filmes em sala de aula não é recente. Contudo, propostas pedagógicas muitas vezes são baseadas apenas no entretenimento, nas produções dos grandes estúdios, na manutenção do colonialismo cultural europeu e hollywoodiano.

A Lei n. 13.006/2014 acrescenta o § 8ª a artigo 26 da Lei n. 9.394/1996 para determinar a exibição de, no mínimo, duas horas mensais de conteúdo audiovisual nacional como elemento integrante da proposta da educação básica, de modo a relacionar cinema e educação, o que, além de valorizar a produção nacional, pode ampliar o repertório cultural dos estudantes. Nossa preocupação, contudo, sugere que o cinema tem que ser visto como cinema conhecimento na medida em que é produção de sentido (DUARTE, 2002) e antecipou com perfeição a era do conhecimento na ficção científica, mas de forma singular conjugando o movimento e o tridimensional (PRUDENTE, 2019a). Sendo assim, para a questão das mino- 
rias, é fundamental o cinema negro, que é uma filmografia das minorias vulneráveis em relação à euro-heteronormatividade (PRUDENTE, 2019b), pois, nessa tendência étnico-cinematográfica, o outro negado se localiza como sujeito histórico na medida em que passa a ser autor da sua própria imagem. Nessa linha de compreensão, é inequívoco o empreendimento de diálogo com Rogério Almeida (2017), que permitirá ancoragem para o discernimento do cinema negro como coadunável no campo disciplinar do cinema e da educação.

É sabido que as tentativas de fragmentação da imagem do ibero-ásio-afro-ameríndio como minoria resultaram em representações estereotipadas destes na sociedade e na mídia, tentando afetar profundamente o modo como eles se relacionam com o outro e como constroem sua autoimagem.

Em seus estudos que constituíram na construção da categoria sobre a dimensão pedagógica do cinema negro, Oliveira e Prudente (2017) e Prudente (2018, 2019a, 2019b, 2019c, 2020) afirmam que esse conceito emergencial poderá contribuir para o processo de afirmação positiva da imagem do ibero-ásio-afro-ameríndio: "é sensato supor que o cinema na era do conhecimento é um cinema epistemológico, tornando-se, a partir da dimensão pedagógica do cinema negro, o cinema das minorias, na medida em que conhecimento e preconceito são antitéticos" (OLIVEIRA; PRUDENTE, 2017, p. 32). Assim, o cinema negro teria uma dimensão pedagógica, pois, além de valorizar a arte e a cultura negra, é um instrumento de luta pela democracia e contra o preconceito.

Portanto, a luta contra o estereótipo da imagem do negro na condição de minoria ibero-afro-ásio-ameríndio, cuja cosmovisão africana primogênita da esfericidade de saberes da circularidade sagrada já conhecia o respeito à diversidade e à biodiversidade, demonstra um esforço especial em favor de uma educação que concorre no sentido da superação do racismo e também de busca de caminhos, em que a africanidade pudesse afirmar a importância da sua cultura como um elemento holístico fundamental para o empreendimento de horizontalidades democráticas.

\section{CONSIDERAÇÕES FINAIS}

Apesar das inúmeras tentativas de apresentar uma visão harmônica das relações raciais no Brasil, empreendidas principalmente por meio de uma "historiografia oficial" presente nos livros didáticos e na mídia, as relações raciais sempre foram conflituosas, marcadas pelas lutas de minorias em favor da afirmação de sua imagem, nos ideais de liberdade e igualdade.

Entretanto, mesmo após mais de 130 anos de abolição oficial da escravatura, mais de 30 anos da promulgação da Constituição Federal de 1988 e quase 20 anos após a Lei Federal $n$. 10.639/2003, que tem como objetivo garantir o ensino de história e cultura afro-brasileira, e da Lei n. 11.645/2008, que inclui o ensino de história e cultura afro-brasileira e indígena nas 
escolas, as conquistas do movimento negro social que compreende agora as relações étnico-raciais, pois aí se estabelece sua afirmação histórica e axiológica, ainda não são amplamente discutidas e nem mesmo fazem parte de muitos PPPs de muitas escolas.

A disseminação de estereótipos em relação aos diferentes dos nomos euro-ocidentais caucasianos, que se constituem na horizontalidade da imagem do ibero-ásio-afro-ameríndio, por meio dos veículos de comunicação de massa foi uma tentativa de afetar profundamente o modo como as minorias constroem suas identidades e se relacionam com o outro. Diante desse quadro, observamos que as escolas com compromisso e consciência multicultural desempenham um importante papel na luta contra a perpetuação de práticas racistas na sociedade. Nesse contexto, influenciar positivamente as crianças em fase de escolarização a construir sua imagem poderia melhorar a autoestima e contribuir para o sucesso delas na escolarização e da própria escolaridade.

\title{
The pedagogical dimension of black cinema and self-esteem for child development in schooling
}

\begin{abstract}
This study intends to observe and develop a critical reflection on the role of self-esteem in child development in monocultural schooling, which is excluding. In view of this, observing the contributions of the pedagogical dimension' category of black cinema, which in this process, can contribute to overcoming that's imposed to black people as a minority. We observe that in contemporary society, racial, socioeconomic and cultural struggles and agendas have transcended the field of literature and have become imagetic struggles, which were projected into class struggles, thus audiovisual productions have gained space and importance. Considering that identities are built in the relationship between the self and the other (HALL, 2011), we can say that the media influences the child's image of himself, which can also influence children's self-esteem when they do not feel represented. In this context, black cinema (PRUDENTE; PASSOS; CASTILHO, 2011; OLIVEIRA; PRUDENTE, 2017; PRUDENTE, 2019a, 2019b, 2019c, 2020) has demonstrated its pedagogical dimension, is fundamental in that it has become a representative of the vulnerable minorized groups in society, which is impregnated by eruheteronormativity, a determining phenomenon for the authoritarianism of verticality of euro-hetero-maleauthoritarian image hegemony, in an attempt to deny the horizontality of the Iberian-Asian-African-Amerindian image, as a minority group and the minority as a hole.
\end{abstract}

Keywords: Black cinema. Childhood. Self-esteem. Schooling. Identity.

\section{REFERÊNCIAS}

ALEXANDRE, I. J. Relações raciais: um estudo com alunos, pais e professores. In: MULLER, M. L. R.; COSTA, C. S. (org.). Cuiabá: EdUFMT, 2010. Coletânea de relações raciais. v. 15. 
ALGARVE, V. A. Cultura negra na sala de aula: pode um cantinho de africanidades elevar a auto-estima de crianças negras e melhorar o relacionamento entre crianças negras e brancas? 2004. Dissertação (Mestrado em Ciências Humanas) - Universidade Federal de São Carlos, São Carlos, 2004.

ALMEIDA, R. de. Cinema e educação: fundamentos e perspectivas. Educação em Revista, v. 33, e153836, 2017.

ARAÚJO, J. Z. A negação do Brasil: o negro na telenovela brasileira. São Paulo: Senac, 2003. BOURDIEU, P. Os três estados do capital cultural. In: NOGUEIRA, M. A; CATANI, A. (org.). Escritos de educação. 2. ed. Petrópolis: Vozes, 1999. p. 71-79.

BRASIL. Constituição Política do Império do Brazil. Brasilia, 1824. Disponivel em: http://www. planalto.gov.br/ccivil_03/Constituicao/Constituicao24.htm. Acesso em: 15 ago. 2020.

BRASIL. Decreto n. 1.331 A. Brasilia, 1854. Disponivel em: http://legis.senado.leg.br/norma/ 392201/publicacao/15632575. Acesso em: 12 jul. 2020.

BRASIL. Decreto n. 7.031 A. Brasilia, 1878. Disponivel em: http://legis.senado.leg.br/norma/ 583976/publicacao/15628699. Acesso em: 12 jul. 2020.

BRASIL. Recenseamento geral do Brasil: 1920. Rio de Janeiro: Ministério da Agricultura, Indústria e Comércio, Diretoria Geral de Estatística, 1920. v. 4. Disponivel em: https://biblioteca. ibge.gov.br/visualizacao/livros/liv6478.pdf. Acesso em: 12 jul. 2020.

BRASIL. Constituição Política da República dos Estados Unidos do Brasil. Brasilia, 1934. Disponivel em: http://www.planalto.gov.br/ccivil_03/constituicao/constituicao34.htm. Acesso em: 15 ago. 2020.

BRASIL. Constituição dos Estados Unidos do Brasil. Brasília, 1946. Disponivel em: http:// www.planalto.gov.br/ccivil_03/Constituicao/Constituicao46.htm. Acesso em: 15 ago. 2020.

BRASIL. Lei de Diretrizes e Bases da Educação - Lei n. 4.024/1961. Brasília, 1961. Disponível em: http://www.planalto.gov.br/ccivil_03/leis/L4024.htm. Acesso em: 5 jul. 2020.

BRASIL. Lei de Diretrizes e Bases da Educação - Lei n. 5.692/1971. Brasilia, 1971. Disponivel em: $\quad$ https://www2.camara.leg.br/legin/fed/lei/1970-1979/lei-5692-11-agosto-1971-357752-publicacaooriginal-1-pl.html. Acesso em: 5 jul. 2020.

BRASIL. Constituição da República Federativa do Brasil. Brasília, 1988. Disponível em: http:// www.planalto.gov.br/ccivil_03/constituicao/constituicao.htm. Acesso em: 15 jul. 2020.

BRASIL. Lei de Diretrizes e Bases da Educação Nacional - Lei n. 9.394/1996. Brasilia, 1996. Disponivel em: http://www.planalto.gov.br/ccivil_03/leis//9394.htm. Acesso em: 5 jul. 2020. 
BRASIL. Lei n. 10.639/2003. Altera a Lei n. 9.394, de 20 de dezembro de 1996, que estabelece as diretrizes e bases da educação nacional, para incluir no currículo oficial da Rede de Ensino a obrigatoriedade da temática "História e Cultura Afro-Brasileira", e dá outras providências. Brasilia, 2003. Disponivel em: http://www.planalto.gov.br/ccivil_03/leis/2003/ | 10.639.htm\#: : :text=LEI\%20No\%2010.639\%2C\%20DE\%209\%20DE\%20JANEIRO\%20 DE\%202003.\&text=Altera\%20a\%20Lei\%20no,\%22\%2C\%20e\%20d\%C3\%A1\%20outras\%20provid\%C3\%AAncias. Acesso em: 5 jul. 2020.

BRASIL. Lei n. 11.645/2008. Altera a Lei n. 9.394, de 20 de dezembro de 1996, modificada pela Lei no 10.639, de 9 de janeiro de 2003, que estabelece as diretrizes e bases da educação nacional, para incluir no currículo oficial da rede de ensino a obrigatoriedade da temática "História e Cultura Afro-Brasileira e Indígena". Brasilia, 2008. Disponível em: http://www. planalto.gov.br/ccivil_03/_Ato2007-2010/2008/Lei/L11645.htm. Acesso em: 5 jul. 2020.

BRASIL. Lei n. 13.006/2014. Acrescenta $\S 8^{\circ}$ ao art. 26 da Lei n. 9.394, de 20 de dezembro de 1996, que estabelece as diretrizes e bases da educação nacional, para obrigar a exibição de filmes de produção nacional nas escolas de educação básica. Brasília, 2014. Disponivel em: http://www.planalto.gov.br/ccivil_03/_Ato2011-2014/2014/Lei/L13006.htm. Acesso em: 5 jul. 2020.

BRASIL. Base Nacional Comum Curricular (BNCC) do ensino fundamental. Brasília, 2017. Disponivel em: http://basenacionalcomum.mec.gov.br/. Acesso em: 23 maio 2020.

DUARTE, R. Cinema \&t educação. Belo Horizonte: Autêntica, 2002.

ELIAS, N.; SCOTSON, J. L. Os estabelecidos e os outsiders: sociologia das relações de poder a partir de uma pequena comunidade. Rio de Janeiro: Zahar, 2000.

FERNANDES, F. A integração do negro na sociedade de classes. São Paulo: Ática, 1978. v. II.

HALL, S. A identidade cultural na pós-modernidade. 9. ed. Rio de Janeiro: DPEtA, 2011.

INSTITUTO BRASILEIRO DE GEOGRAFIA E ESTATISTICA. Pesquisa Nacional por Amostra de Domicilios Contínua. Rio de Janeiro: IBGE, 2018. Disponivel em: https://www.ibge.gov.br/estatisticas/sociais/populacao/25844-desigualdades-sociais-por-cor-ou-raca.html?=\&tt= resultados. Acesso em: 25 jul. 2020.

OLIVEIRA, F. R. de; PRUDENTE, C. L. A lusofonia de horizontalidade da imagem do ibero-ásio-afro-amerindio versus a verticalidade da hegemonia imagética do euro-hétero-machoautoritário: a dimensão pedagógica do cinema negro posto em questão. Lisboa: Aulp, 2017. v. 1.

PAIVA, V. Um século de educação republicana. Pró-Posições, v. 1, n. 2, p. 7-18, jul. 1990. Disponivel em: https://www.fe.unicamp.br/pf-fe/publicacao/1675/2-artigo-paivav.pdf. Acesso em: 26 jul. 2020. 
PEREIRA, J. G. Colégio São Benedito - a escola na construção da cidadania. In: NASCIMENTO, T. A. Q. R. do et al. Memórias da educação: Campinas (1850-1960). Campinas: Editora da Unicamp, Centro de Memória, 1999.

PRUDENTE, C. A fragmentação do mito da democracia racial e a dimensão pedagógica do cinema negro. Revista Internacional em Língua Portuguesa, n. 38, p. 157-171, 6 ago. 2020. Disponivel em: https://doi.org/10.31492/2184-2043.RILP2020.38/pp.157-171. Acesso em: 6 ago. 2020.

PRUDENTE, C. L. A dimensão pedagógica do cinema negro como arte de afirmação positiva do afrodescendente nas relações étnico-raciais do resgate do traço epistemológico da imagem ibero-ásio-afro-ameríndio. In: CONFERÊNCIA FORGES, 8., 2018, Lisboa. Anais [...]. Lisboa: Fórum da Gestão do Ensino Superior nos Paises e Regiões de Língua Portuguesa, 2018. Disponivel em https://www.aforges.org/wp-content/uploads/2019/10/TEXTO-COMPLETO-A-DIMENS\% c3\%830-PEDAG\%c3\%93GICA-D0-CINEMA-NEGRO.pdf. Acesso em: 3 maio 2020.

PRUDENTE, C. L. A dimensão pedagógica do cinema negro: uma arte ontológica de afirmação positiva da imagem do ibero-ásio-afro-ameríndio: a origem do cinema negro e sua dimensão pedagógica. In: PRUDENTE, C. L.; SILVA, D. C. (org.). A dimensão pedagógica do cinema negro: aspectos de uma arte para a afirmação ontológica do negro brasileiro: o olhar de Celso Prudente. 2. ed. São Paulo: Anita Garibaldi, 2019a. p. 67-90.

PRUDENTE, C. L. Étnico léxico: para compreensão do autor. In: PRUDENTE, C. L.; SILVA, D. C. (org.). A dimensão pedagógica do cinema negro: aspectos de uma arte para a afirmação ontológica do negro brasileiro: o olhar de Celso Prudente. 2. ed. São Paulo: Anita Garibaldi, 2019b. p. 171-177.

PRUDENTE, C. L. A dimensão pedagógica do cinema negro: a imagem de afirmação positiva do ibero-ásio-afro-amerindio. Revista Extraprensa, São Paulo, v. 13, n. 1, p. 6-25, 2019 c.

PRUDENTE, C. L.; PASSOS, L. A.; CASTILHO, S. D. Grito do morro: reflexões para o discernimento da construção da imagem positiva do negro. In: PRUDENTE, C. L. Cinema negro: algumas contribuições reflexivas para a compreensão da questão do afrodescendente na dinâmica sociocultural da imagem. São Paulo: Fiuza, 2011. v. 4.

PRUDENTE, W. Crime de escravidão. Rio de Janeiro: Lumen Juris, 2006.

SANTANA, M. A. Relações raciais e gestão escolar. In: MULLER, M. L. R.; COSTA, C. S. (org.). Cuiabá: EdUFMT, 2013. Coletânea de relações raciais. v. 23.

SANTOS, C. L. A disputa do imaginário: as representações do cangaço no cinema nacional (1950). Domínios da Imagem, Londrina, ano III, n. 6, p. 67-74, maio 2010. Disponivel em: http://www.uel.br/revistas/uel/index.php/dominiosdaimagem/article/view/23231/17000. Acesso em: 11 maio 2020. 
SILVA, A. M. P. da. A escola de Pretextato dos Passos e Silva: questões a respeito das práticas de escolarização no mundo escravista. Revista Brasileira de História da Educação, n. 4, p. 146-166, jul./dez. 2002.

SPIVAK, G. C. Pode o subalterno falar? Tradução Sandra Regina Goulart Almeida, Marcos Pereira Feitosa e André Pereira Feitosa. Belo Horizonte: Editora da UFMG, 2010.

TIBA, I. Quem ama educa. São Paulo: Gente, 2002. 